\title{
Göğüs Hastalıkları Servisinde Yatarak Tedavi Gören 65 Yaş Üstü Geriatrik Hasta Popülasyonun Genel Özellikleri
}

\author{
General Characteristics of Over 65 Years of Geriatric Patient Population in Respiratory Disease \\ Service
}

Fatih ÜZER 1

(i) 0000-0001-9318-0458

Ruşen UZUN ${ }^{2}$

(1) 0000-0001-6575-5066

\section{ÖZ}

Amaç: $\mathrm{Bu}$ çalışmada; göğüs hastalıkları servisinde yatmış olan 65 yaş ve üstü hastaların bireysel özelliklerini ve yaşlı bireylerin gögüs hastalıkları servislerine yatışlarını değerlendirmek amaçlanmıştır.

Gereç ve Yöntemler: Çalışmaya 1 Ocak 2017-31 Aralık 2017 tarihleri arasında Antalya Eğitim ve Araştırma Hastanesi Gögüs Hastalıkları servisinde yatmış olan 587 hasta dahil edildi. Dünya Sağlık Örgütü (DSÖ)'ne göre 65 yaş ve üstü kişiler yaşlı olarak kabul edildi. Bu hastaların demografik verileri, yatış nedenleri, yatış gün sayısı, posterior anterior akciğer grafileri ve taburculuk durumları veri formuna kayıt edildi. Çalışmaya 65 yaş ve üstünde olan tüm hastalar dahil edilirken, 65 yaş altındaki kişiler çalışma dışı bırakıldı. Çalışma döneminde birden çok hastane yatışı olanların ilk yatışları dikkate alındı.

Bulgular: Çalışmaya ortalama yaşı 76,5 7,4 yıl olan 587 hasta dahil edildi. Hastaların göğüs hastalıkları servisine ortanca yatış süreleri 7 (1-88) gün olarak tespit edildi. Hastaların yatış nedenlerine bakıldığında sıklık sırasına göre; kronik obstrüktif akciğer hastalığı $(\mathrm{KOAH})$ alevlenme $(\mathrm{n}=181 ; \% 30,8)$, pnömoni $(\mathrm{n}=166 ; \% 28,3)$, non-spesifik alt solunum yolu enfeksiyonu $(\mathrm{n}=78 ; \% 13,3)$ ve astım atak $(\mathrm{n}=63 ; \% 10,7)$ olarak saptand.. Ek hastalığ olan 419 $(\% 71,4)$ hasta olup, en sik tespit edilen ek hastalıklar kardiyovasküler $(n=267 ; \% 63,7)$, endokrinolojik $(\mathrm{n}=114 ; \% 27,2)$ ve nörolojik $(\mathrm{n}=91 ; \% 21,7)$ hastallklar idi. Takip edilen hastaların mortalite oranı $\% 4,4(n=26)$ olarak tespit edildi.

Sonuç: Sonuç olarak, 65 yaş ve üzeri geriatrik hastalıklarda göğüs hastalıkları servislerine en sık yatırılma nedenleri KOAH alevlenme ve pnömonidir. En sık eşlik eden komorbid durumlar ise kardiyovasküler hastalıklardır.

Anahtar kelimeler: Gögüs hastalıkları; hastane yatışı; KOAH; pnömoni.

\footnotetext{
ABSTRACT

Aim: The aim of this study was to evaluate the individual characteristics of the patients aged 65 and over who were hospitalized in the department of respiratory diseases.

Material and Methods: The study included elderly patients who were hospitalized in the Respiratory Diseases Department at Antalya Training and Research Hospital between 1 January 2017 and 31 December 2017. According to the World Health Organization (WHO), people aged 65 and over were considered as older. The demographic data, reasons of hospitalization, number of days of hospitalization, posterior anterior chest radiographs and discharge status were recorded in the data form. All patients aged 65 years and over were included in the study, while those under 65 years of age were excluded from the study. In the study period, the first hospitalizations of the patients who were readmission more than one were taken into consideration.

Results: A total of 587 patients with mean age of $76.5 \pm 7.4$ years were enrolled in the study. Median hospital stay duration of patients was 7 (1-88) days. Reasons for hospitalization by frequency order were; chronic obstructive pulmonary disease (COPD) exacerbation $(n=18$; $30.8 \%)$, pneumonia $(n=166 ; 28.3 \%)$, non-specific lower respiratory tract infection $(n=78$; $13.3 \%)$ and asthma attack $(n=63 ; 10.7 \%)$. There were $419(71.4 \%)$ patients with comorbid diseases, and the most common detected diseases were including cardiovascular $(n=267$; $63.7 \%)$, endocrinological $(n=114 ; 27.2 \%)$ and neurological $(n=91 ; 21.7 \%)$ diseases. The mortality rate of the patients was $4.4 \%(n=26)$.

Conclusion: As a result, COPD exacerbation and pneumonia are the most common causes of pulmonary diseases in geriatric patients older than 65 years. The most common comorbid conditions are cardiovascular diseases.
}

Corresponding Author

Fatih ÜZER

uzerfatih@gmail.com

Geliş Tarihi / Received : 01.11.2018

Kabul Tarihi / Accepted : 08.02.2019

Çevrimiçi Yayın Tarihi /

Available Online

: 20.02.2019 


\section{GÍRIŞ}

Doğuștan beklenen yaşam süresinin artması ülkelerin refah düzeyinin bir göstergesi olmakla birlikte, bu durum pek çok sorunu da beraberinde getirmektedir. Yaşlı nüfusun artmasıyla birlikte sayısı ve şiddeti artan sağlık sorunlar1, azalan fonksiyonel yetenekler, ekonomik zorluklar, sosyal statüde değişiklikler, eş, arkadaş kayıpları gibi pek çok sorunla karşılaşılmaktadır. Dünya Sağlık Örgütü (DSÖ) geriatrik yaşlılık çağını 65 yaş ve üstünü yaşlı, 85 yaş ve üzerini ise çok yaşlı olarak ifade etmiştir. Dünya nüfusunun yaşlılara düşen payı zaman içinde artmaktadır. 2050 yılına kadar dünya nüfusunun \%21'ni yaşlıların oluşturacağı tahmin edilmektedir (1).

Yaşılı nüfusun artması, yaşlıların sorunlarını daha iyi algılamayı gerekli kılmıştır. Yaşlı bireyler hastalıklara daha sık ve daha çabuk yakalanmaktadırlar. Yaşlıların çoğunda birden fazla sağlık sorununa sıklıkla rastlanmakta ve buna bağlı olarak sağlık kurumlarına daha sık başvuru yapılmaktadır. Geriatrik hastaların hastanede kalış süreleri uzamakta, mortalite hızları ve tedavi maliyetleri yüksek olmaktadır (2). Yaşlı hastalar, birçok branşta önemli bir orana sahiptir, göğüs hastalıkları da yaşlı hasta popülasyonun sık tedavi edildiği servislerden biridir. Yapılan çalışmalarda göğüs hastalıkları servisinde çoklu komorbiditesi olan yaşlı hastalar önemli bir oranı oluşturmaktadır (3-5). Göğüs hastalıklarının temel uğraşı alanı olan kronik obstrüktif akciğer hastalığı (KOAH), pnömoni ve akciğer kanseri gibi hastalıklar genel olarak yaşlı nüfusta daha sık görülmektedir. Bu çalışmada; göğüs hastalıkları servisinde yatmış olan 65 yaş ve üstü hastaların bireysel özelliklerini ve yaşlı bireylerin gögüs hastalıkları servislerine yatışlarını değerlendirmek amaçlanmıştır.

\section{GEREC VE YÖNTEMLER}

$\mathrm{Bu}$ çalışmaya 1 Ocak 2017-31 Aralık 2017 tarihleri arasında Antalya Eğitim ve Araştırma Hastanesi Göğüs Hastalıkları servisinde yatmış olan 587 hasta dahil edildi. DSÖ’ye göre 65 yaş ve üstü kişiler yaşlı olarak kabul edildi. Bu hastaların demografik verileri, yatış nedenleri, yatış gün sayısı, akciğer grafileri ve taburculuk durumları veri formuna kayıt edildi. Çalışmaya 65 yaş ve üstünde olan tüm hastalar dahil edilirken, 65 yaş altındaki kişiler çalışma dışı bırakıldı. Çalışma döneminde birden çok hastane yatışı olanların ilk yatışları dikkate alındı. Çalışma, Antalya Eğitim ve Araştırma Hastanesi Etik Kurulu tarafindan (11.10.2018 tarih ve 19/5 nolu karar) onaylanmıştır.

\section{İstatistiksel Analiz}

Tanımlayıcı istatistikler ortalama, standart sapma, ortanca, frekans ve yüzde değerleri ile sunulmuştur. Grupların cinsiyet dağılımlarının farklılıklarının incelenmesi amacı ile ki-kare testi yapılmıştır. Farklı olan grupların tespit edilmesi amacı ile Bonferroni yöntemi uygulanmıştır. Cinsiyete göre yaş ve yatış günü açısından farklılığın incelenmesi için Mann-Whitney $U$ testi kullanılmıştır. Çalışmada 0,05'ten küçük p değerleri istatistiksel olarak anlamlı kabul edilmiştir. Analizler SPSS 22.0 (SPSS/IBM, Chicago, IL, USA) paket programı ile yapılmıştır.

\section{BULGULAR}

Çalışmaya ortalama yaşı $76,5 \pm 7,4$ (65-95) yıl olan 352 (\%60) erkek ve 235 (\%40) kadın hasta dahil edildi. Hastaların göğüs hastalıkları servisine ortanca yatış süreleri 7 (1-88) gün olarak tespit edildi. Hastaların temel özellikleri Tablo 1'de verildi. Göğüs hastalıkları servisinde takip edilen yaşı lı erkek hastaların ortalama yaşı $75,5 \pm 7,3$ yıl iken yaşlı kadın hastaların ortalama yaşı $77,7 \pm 7,5$ olarak tespit edildi $(p<0,001)$. Ortanca yatış süresi erkek hastalarda 7 (1-39) gün, kadın hastalarda 7 (188) gün olarak saptand $1(p=0,631)$. Hastaların yatış nedenlerine bakıldığında sıklık sırasına göre; KOAH alevlenme $(\mathrm{n}=181 ; \% 30,8)$, pnömoni $(\mathrm{n}=166 ; \% 28,3)$, non-spesifik alt solunum yolu enfeksiyonu (ASYE) $(\mathrm{n}=78 ; \% 13,3)$ ve astım atak $(\mathrm{n}=63 ; \% 10,7)$ olarak saptand1. Kadın hastalarda en sık yatış nedenleri pnömoni $(\% 29,2)$, astım atak $(\% 23,5)$, non-spesifik ASYE $(\% 18,6)$ iken, erkeklerde en sik nedenler KOAH alevlenme $(\% 45,5)$, pnömoni $(\% 32,5)$ ve non-spesifik ASYE $(\% 11,7)$ olarak tespit edildi. Hastaların hastaneye yatış nedenlerinin cinsiyete göre farklılık gösterdiği tespit edildi ( $<<0,001$; Tablo 2; Şekil 1).

Hastaların medeni durumlarına bakıldığında 412 (\%70,2) hasta evli, $45(\% 7,7)$ hasta dul, $14(\% 2,4)$ hasta bekar olduğu görüldü, $116(\% 19,8)$ hastanın ise medeni durumu dosyada belirtilmediği için ulaşılamad. Posterior anterior akciğer grafisinde saptanan bulgular $181(\% 30,8)$ normal, $154(\% 26,2)$ infiltrasyon, $55(\% 9,4)$ atelektazi, $49(\% 8,3)$ kitle, $42(\% 7,2)$ intersitisyel patern, $23(\% 3,9)$ efüzyon ve $83(\% 14,1)$ diğer (pnömotoraks, mediasten genişlemesi vs.) olarak not edildi (Tablo 3). Ek hastalığı olan 419 $(\% 71,4)$ hasta olup, en sik tespit edilen ek hastalıklar

Tablo 1. Hastaların genel özellikleri $(\mathrm{n}=587)$

\begin{tabular}{lcc}
\hline & & $\mathbf{n}(\mathbf{\%})$ \\
\hline Cinsiyet & Kadın & $352(60,0)$ \\
Sigara öyküsü & Erkek & $235(40,0)$ \\
Ek hastalık & & $244(41,6)$ \\
\hline
\end{tabular}

Tablo 2. En sık hastane yatış nedenleri $(\mathrm{n}=534)$

\begin{tabular}{lccc}
\hline Hastalık & $\begin{array}{c}\text { Kadın } \\
(\mathbf{n = 2 2 6})\end{array}$ & $\begin{array}{c}\text { Erkek } \\
(\mathbf{n = 3 0 8})\end{array}$ & $\mathbf{p}$ \\
\hline KOAH alevlenme & $41(\% 18,1)^{\mathrm{a}}$ & $140(\% 45,5)^{\mathrm{b}}$ & \\
Pnömoni & $66(\% 29,2)^{\mathrm{a}}$ & $100(\% 32,5)^{\mathrm{a}}$ & \\
Astım atak & $53(\% 23,5)^{\mathrm{b}}$ & $10(\% 3,2)^{\mathrm{a}}$ & $<\mathbf{0 , 0 0 1}$ \\
Non-spesifik ASYE & $42(\% 18,6)^{\mathrm{b}}$ & $36(\% 11,7)^{\mathrm{a}}$ & \\
Pulmoner emboli & $24(\% 10,6)^{\mathrm{a}}$ & $22(\% 7,1)^{\mathrm{a}}$ & \\
\hline
\end{tabular}

KOAH: Kronik obstrüktif akciğer hastalığı, ASYE: Alt solunum yolu enfeksiyonu (trakeit, bronşit vs.), Post hoc test sonucuna göre a ve b harfleri yüzde değerleri farklı olan grupları gösterir $(b>a)$

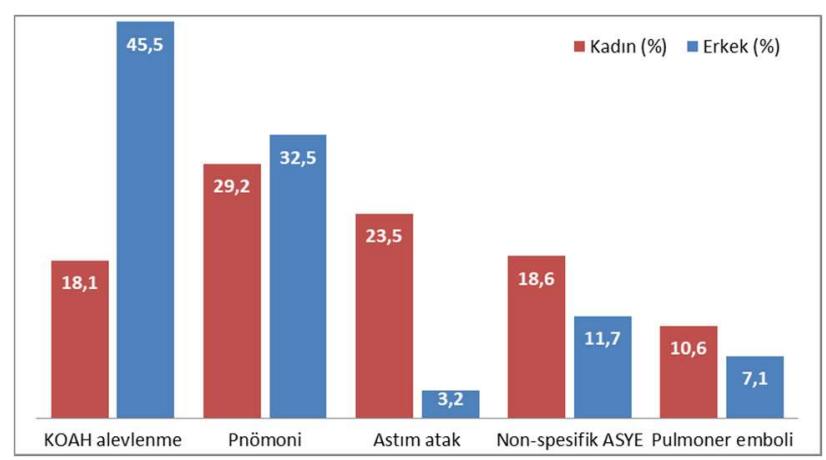

Şekil 1. Hastane yatış nedenleri, KOAH: Kronik obstrüktif akciğer hastalığı, ASYE: Alt solunum yolu enfeksiyonu 
kardiyovasküler $(n=267, \% 63,7)$, endokrinolojik $(n=114$; $\% 27,2)$ ve nörolojik ( $\mathrm{n}=91 ; \% 21,7)$ hastalıklar idi. Malignitesi olanların oranı $\% 7(n=41)$ olarak tespit edildi. Çalışmaya alınan hastaların taburculuk durumlarına bakıldığında $413(\% 70,4)$ 'ü hasta haliyle taburcu olmuşken, $122(\% 20,8)$ 'si şifa ile $13(\% 2,2)$ 'ü ise yazılı onam verip kendi isteği ile taburcu oldu. Takip edilen hastaların mortalite oran $\% 4,4(\mathrm{n}=26)$ olarak tespit edildi. Mortalite nedenlerine göre hastaların dağılımı Şekil 2'de gösterilmiştir.

\section{TARTIŞMA}

Göğüs hastalıkları servisinde yatan 65 yaş üstü geriatrik hastaların incelendiği bu çalışmada hastaların büyük bir kısmının erkek olduğu, en sık yatış nedeninin $\mathrm{KOAH}$ alevlenme olduğu ve en sik saptanan akciğer grafisi bulgusunun ise normal olduğu tespit edildi. Mortalitenin en sık sebebinin pnömoni olduğu saptand1. Ayrıca bu hasta popülasyonun önemli bir özelliği olan komorbid hastalıkların varlığı, çalışmaya alınan hastaların büyük bir kisminda mevcuttu.

Yaşlanma süreci hastalık prevalanslarında artma, komorbiditeler, hayat kalitesinde bozulma, hastane yatışları ve mortalite ile ilişkilidir. KOAH önemli bir kronik hastalık olup özellikle yaşlıları etkileyen bir hastalıktır. Yaşlanma, inhale edilen zararlı partikül ve gazların kümülatif etkisinin bir göstergesi olarak kabul edilebilir (6-8). KOAH prevalansı yaşla birlikte artmaktadır, 45 yaş üstünde \%8-12 dolaylarında iken, 65 yaş üstünde bu oran \%12-22 seviyelerine çıkabilmektedir (9). KOAH yaşlı popülasyonda diğer yaşlardan üç-beş kat daha sık olup hastane yatışı ve ölümün yaşl1lıkta ikinci en s1k nedenidir (10). Bu çalışmada yatarak tedavi gören hastaların yaklaşık üçte birinin KOAH alevlenme ile yattığı tespit edildi. Yaşlı popülasyonda tek başına KOAH

Tablo 3. Posterioranterior akciğer grafisi bulguları $(n=587)$

\begin{tabular}{lc}
\hline Bulgu & $\mathbf{n}(\mathbf{\%})$ \\
\hline İnfiltrasyon & $154(26,2)$ \\
Normal & $181(30,8)$ \\
Atelektazi & $55(9,4)$ \\
İntersitisyel & $42(7,2)$ \\
Kitle & $49(8,3)$ \\
Efüzyon & $23(3,9)$ \\
Diğer (pnömotoraks, mediasten genişlemesi vs.) & $83(14,1)$ \\
\hline
\end{tabular}

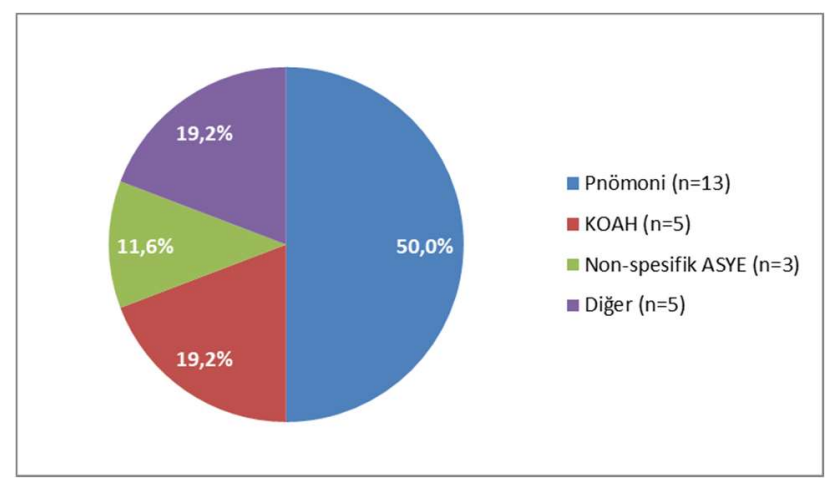

Şekil 2. Mortalite nedenleri, KOAH: Kronik obstrüktif akciğer hastalı̆̆ı, ASYE: Alt solunum yolu enfeksiyonu nadiren görülmektedir, komorbiditeler çok sık beraberlik göstermektedir. Bu çalışmada da hastaların önemli bir kısmının komorbit hastalıkları olduğu görülmüştür.

Akciğer enfeksiyonlarının sıklığı yaşla beraber artmaktadır. Gençlere göre yaşlılarda pnömoni nedenli hastane yatışı ve mortalite oranı yüksektir (11). İlerleyen yaş ile birlikte komorbit durumların artması (KOAH, kardiyovasküler hastalıklar, endokrinolojik hastalıklar, nörolojik hastalıklar), yutma fonksiyonunda bozulma, tekrarlayan aspirasyonlar, kognitif fonksiyonlarda bozulma, yetersiz ve dengesiz beslenme, immünsupresif tedavi gibi çeşitli durumların varlığında pnömoni riski artar (5,12-14). Erkek cinsiyet ve sigara içimi yaşlilarda pnömoni için bağımsız risk faktörüdür $(15,16)$. Pnömoni ile yatan hastaların \%60,2 $(n=100)$ 'si erkek idi. Pnömoni nedeniyle ölümlerin büyük bir kısmı bu hasta grubunda olmaktadır. Bu çalışmada ikinci en sık hastane yatış nedeninin pnömoni olduğu tespit edilmiştir. Pnömoni nedenli yatış yapılan olguların tamamı toplumda gelişen pnömoni idi. Türkiye'de yapılan bir çalışmada 65 yaş üzerindeki pnömoni olgularında ölüm oranının \%10-30 oranında olduğu bildirilmiştir (17). Bu çalışmada ise bu oran \%7,8 olarak tespit edildi. Ayrıca tüm ölümlerin yarısının pnömoni nedenli olduğu sonucuna ulaşıldı.

Literatürde yaşlı hastalarda astım tanısının zor olduğu ve diğer birçok hastalıkla karıştığı için yanlış tanı aldığ bildirilmektedir (18). Bu hasta popülasyonunda astım tanısı yetersiz kalmakta ve tedaviden istenilen verim beklendiği gibi olmamaktadır. Diğer yandan bu yaş grubunda mortalite oldukça yüksektir. Yaşlanmaya bağlı akciğerlerde meydana gelen bazı değişikler, ek hastalıklar, çoklu ilaç kullanımı tipik astım tablosunu yaşlılarda olduğundan farklı gösterebilmekte ve tanıda zorluk yaratmaktadır. $\mathrm{Bu}$ nedenle başta kronik KOAH olmak üzere tüm ayırıcı durumları göz önüne alarak doğru tanı konulmalıdır. $\mathrm{Bu}$ çalışmada yatarak tedavi gören hastaların \%10,7'sinin astım olduğu ve astım ile yatanların büyük bir kısmının ise kadın olduğu görüldü.

Pulmoner emboli sıklığı ve mortalitesi yaş ile giderek artmaktadır. Literatüre bakıldığında yapılan çalışmalarda hastaların ortalama yaşının 47-76 arasında geniş bir aralıkta olduğu görülmektedir (19-21). Yaşlı hastalarda pulmoner emboli semptomları, bu yaş grubunda sık görülen kardiyopulmoner hastalıkların semptomları ile karıştığından ya da bu semptomların yaşlılığa bağlaması nedeniyle pulmoner emboli tanısını koymak bazen zor olabilmektedir. $\mathrm{Bu}$ çalışmada tüm hastaların \%7,8'nin pulmoner emboli nedeniyle ile hastaneye yatırıldığı tespit edildi. Miniati ve ark. (22) erkek cinsiyeti pulmoner emboli için bir risk faktörü olarak kabul etmektedir. Ancak bu çalışmada göğüs hastalıkları servisine pulmoner emboli nedeniyle yatan hastaların cinsiyet bakımından bir birine üstünlük kurmadığı tespit edildi.

Sigara önlenebilir ölüm nedenleri içinde en ön sıralarda gelmektedir. Ülkemizde her yıl yaklaşık olarak 100-110 bin kişi sigaraya bağlı hastalıklardan dolayı hayatını kaybetmektedir (23). Sigara bağımlılı̆̆ı tüm yaş gruplarında görülebilen bir durumdur. Sigara içimi kardiyovasküler hastalıklar, serebrovasküler olay, kanser ve akciğer hastalığının bilinen risk faktörüdür. Yaşlılıkta sigara içimi mortaliteyi artırmaktadır ve sigara içmeyi sürdüren yaşlılarda mortalite, içmeyenlerin yaklaşık iki katıdır $(24,25)$. Çin'de yapılan bir çalışmada 70 yaş üstü 
sigara içimi ile kardiyovasküler hastalık, kanser ve solunum hastalığından mortalite ile devam eden sigara içimi arasında önemli ilişki bulunmuştur (26). Yaşlilarda sigara içimi mortaliteyi artırmaktadır. Sigara bırakılmasıyla sağ kalımda uzama ve hastalıkların riskinde azalma sağlanmaktadır. $\mathrm{Bu}$ çalışmaya dahil edilen hastaların \%41,6'sının sigara kullanma öyküsü olup mortal seyreden olguların da \%30,8 $(n=8)$ 'inin sigara kullanma öyküsü mevcuttu.

Akciğer kanserinin görülme sıklığı yaşla birlikte artmaktadır. Her iki cinsiyette de en sık görülen kanser türlerinden biridir. Akciğer kanseri yaşlilarda kansere bağlı ölümlerin en sık nedenidir. Gerek ayaktan tedavi maliyeti gerek çoklu hastane yatışları akciğer kanseri maliyetini artırmaktadır. Gelişmiş ülkelerde ortalama hastalık yaşı 70 olup olguların yaklaşık üçte ikisi 65 yaş üzerindedir $(27,28)$. Bu oranın gelecek birkaç dekatta daha da artması beklenmektedir (29). Bu çalışmada yatarak tedavi gören hastaların \%6,3'nün akciğer kanseri nedeniyle yattığı ya da tanı araştırılması için yatırıldığ tespit edildi. $\mathrm{Bu}$ olguların önemli bir kısmı erkek olup, ortalama yaşı ise 74 'tü.

Beklenen yaşam süresindeki artış nedeniyle yaşlı hastalara daha sık radyolojik tetkikler yapılmaktadır. Yaşlılardaki göğüs görüntüleme belirli bir bilgi ve deneyim gerektirir. Yaşlılarda akciğer görüntülemesi yapılırken bazı problemler yaşanabilir. Bunlar; temel olarak hastaların kendileriyle ilgili olup, hareketsizlik, uzun nefes tutmada imkansızlık, komorbiditelerin varlığı gibi durumlardır (30). Yaşlı hastalarda en önemli görüntüleme yöntemi konvansiyonel akciğer grafisidir. İnfiltrasyonları saptamak, hastalığın yayılımını ve komplikasyonlarını tespit etmek, tedaviye yanıtı gösterme grafinin başlıca rollerindendir. $\mathrm{Bu}$ çalışmada akciğer grafisi çekilen hastalarda en sik saptanan bulgu normal akciğer grafisi bulgusu olup, en sik tespit edilen patolojik bulgu ise infiltrasyonlardi.

Bu çalışmada değerlendirilen geriatrik hastalarda en sık saptanan komorbid durumların kardiyovasküler hastalıklar $(\% 45,4)$ olduğu tespit edildi. Bu çalışmaya paralel olarak Türkiye'de yapılan çalışmalarda; Çakmak ve ark. (5) 85 yaş üstü geriatrik hastalarda, Balbay ve ark. (4) ise 90 yaş üstü geriatrik hastalarda en s1k komorbit durum olarak kardiyovasküler hastalıklar olduğunu bulmuşlardır. Bunun yanında Kaplan ve ark. (3) tarafindan yapılan çalışmada da 65 yaş ve üzeri pnömoni tanısı alan olgularda kardiyovasküler komorbiditeyi \%36,2 olarak bulmuşlardır.

Sonuç olarak, 65 yaş ve üzeri geriatrik hastalıklarda göğüs hastalıkları servislerine en sık yatırılma nedenleri KOAH alevlenme ve pnömonidir. En sik eşlik eden komorbid durumlar ise kardiyovasküler hastalıklardır. Hastaların büyük bir çoğunluğu şifa ile taburcu edilebilmiştir. Mortalitenin en az yarısı pnömoniye bağlı meydana gelmektedir. $\mathrm{Bu}$ yaş grubunda pnömonin hastane yatışı ve mortalitesinin yüksek olmasından dolayı yakından takip edilmesi gerekmektedir.

\section{KAYNAKLAR}

1. Özyürek BA, Ertürk A. Yaşlılarda pnömoni. İçinde: Ertürk A, Bahadır A, Koşar F, Editörler. Yaşlılık ve solunum hastalıkları. Ankara: TÜSAD Eğitim Kitapları Serisi; 2018. s.214-61.
2. Bilir N. Yaşlanan toplum. Kutsal YG, editör. Yaşlılıkta Kaliteli Yaşam. Ankara: Hacettepe Üniversitesi Hastaneleri Basımevi; 2007. s.11-5.

3. Kaplan V, Clermont G, Griffin MF, Kasal J, Watson RS, Linde-Zwirble WT, et al. Pnemonia: still the old man's friend? Arch Intern Med. 2003;163(3):317-23.

4. Balbay EG, Cangür Ş, Alaşan F, Tanrıverdi E. Göğüs Hastalıkları Servisinde İzlenen 90 Yaş ve Üzeri Geriatrik Hastaların Değerlendirilmesi. Tuberk Toraks. 2014;62(1):22-6.

5. Çakmak ME. Göğüs hastalıkları servisimizde izlenen 85 yaş ve üzeri geriatrik hastaların değerlendirilmesi. İzmir Göğüs Hastanesi Dergisi. 2016;30(3):167-72.

6. Sorino C, Battaglia S, Scichilone N, Pedone C, Antonelli-Incalzi R, Sherrill D, et al. Diagnosis of airway obstruction in elderly: Contribution of SARA study. Int J Chron Obstruct Pulmon Dis. 2012;7:38995.

7. Lundback B, Lindberg A, Lindstrom M, Rönmark E, Jonsson AC, Jönsson E et al. Not 15 but $50 \%$ of smokers develop COPD? Report from the obstructive lung disease in Nothern Sweden Studies. Respir Med. 2003;97(2):115-22.

8. Lalley PM. The aging respiratory system-pulmonary structure function and neural control. Respir Physiol Neurobiol. 2013;187(3):199-210.

9. Mahesh PA, Jayaraj BS, Chaya SK, Lokesh KS, McKay AJ, Prabhakar AH, et al. Variation in the prevalence of chronic bronchitis among smokers-a cross sectional study. Int $\mathrm{J}$ Tuberc Lung Dis. 2014;18(7):862-9.

10. Sökmen BK, Akman C. Yaşlı Hastalarda Radyolojik Görüntüleme. İçinde: Ertürk A, Bahadır A, Koşar F, Editörler. Yaşlılık ve solunum hastalıkları. Ankara: TÜSAD Eğitim Kitapları Serisi;2018. s.69-77.

11. Gavazzi G, Krause KH. Ageing and infection. Lancet Infect Dis. 2002;2(11):659-66.

12. Loeb M, McGeer A, McArthur M, Walter S, Simor AE. Risk factors for pneumonia and other lower respiratory tract infections in elderly residents of long-term care facilities. Arch Intern Med. 1999;159(17):2058-64.

13. Riquelme R, Torres A, El-Ebiary M, de la Bellacasa JP, Estruch R, Mensa J, et al. Community-acquired pneumonia in the elderly: A multivariate analysis of risk and prognostic factors. Am J Respir Crit Care Med. 1996;154(5):1450-5.

14. Ruiz M, Ewig S, Marcos MA, Martinez JA, Arancibia F, Mensa J, et al. Etiology of community- acquired pneumonia: impact of age, comorbidity, and severity. Am J Respir Crit Care Med. 1999;160(2):397-405.

15. Ochoa-Gondar O, Vila-Corcoles A, de Diego C, Arija $\mathrm{V}$, Maxenchs $\mathrm{M}$, Grive $\mathrm{M}$, et al. The burden of community acquired pneumonia in the elderly: the Spanish EVAN-65 study. BMC Public Health. 2008;8:222.

16. Marrie TJ, File TM Jr. Bacterial pneumonia in older adults. Clin Geriatr Med. 2016;32(3):459-77.

17. Özhan MH. Geriatrik Olgularda Pnömoni. Review Turkiye Klinikleri J Pulm Med-Special Topics. 2017;10(3):177-83.

18. Yorgancıŏlu A, Şakar Coşkun A. Yaşlılarda astım tanısı farklı mıdır? Tüberküloz Toraks. 2012;60(1):815. 
19. Kostadima E, Zakynthinos E. Pulmonary embolism: pathophysiology, diagnosis, treatment. Hellenic J Cardiol. 2007;48(2):94-107.

20. Bateson D, Butcher BE, Donovan C, Farrell L, Kovacs G, Mezzini T, et al. Risk of venous thromboembolism in women taking the combined oral contraceptive: A systematic review and meta-analysis. Aus Fam Physician. 2016;45(1):59-67.

21. Caprini JA. Thrombosis risk assessment as a guideto quality patient care. Dis Mon. 2005;51(2-3):70-8.

22. Miniati M, Prediletto R, Formichi B, Marini C, Di Ricco G, Tonelli L, et al. Accuracy of clinical assessment in the diagnosis of pulmonary embolism. Am J Respir Crit Care Med. 1999;159(3):864-71.

23. Doğanay S, Sözmen K, Kalaça S, Ünal B. Türkiye'de toplumda sigara içme sıklığı nasıl değişsiyor? Türkiye Halk Sağlığ1 Dergisi. 2012;10(2):93-115.

24. Smith SS, Fiore MC. The epidemyology of tobacco use, dependence and cessation in United States. Prim Care. 1999;26(3):433-61.

25. Karnath B. Smoking cessation. Am J Med. 2002;112(5):399-405.

26. Ho SC, Zhan SY, Tang JL, Chan SG, Woo J. Smoking and mortality in an older Chinese cohort. J Am Geriatr Soc. 1999;47(12):1445-50.

27. Torre LA, Siegel RL, Ward EM, Jemal A. Global cancer incidenceand mortality rates and trends-an update. Cancer Epidemiol Biomarkers Prev. 2016;25(1):16-27.

28. Siegel RL, Miller KD, Jemal A. Cancer statistics, 2016. CA Cancer J Clin. 2016;66(1):7-30.

29. Barta JA, Zinner RG, Unger M. Lung cancer in the older patient. Clin Geriatr Med. 2017;33(4):563-77.

30. Bonomo L, Larici AR, Maggi F, Schiavon F, Berletti R. Aging and the respiratory system. Radiol Clin North Am. 2008;46(4):685-702. 